Original Paper

\title{
Describing the Epidemiology of COVID-19 in Nigeria: An Analysis of the First Year of the Pandemic
}

Obinna Oleribe, MD, PhD

Olatayo Olawepo, MD

Oliver Ezechi, MD

Princess Osita-Oleribe, MD

Michael Fertleman, MD

Simon D Taylor-Robinson, MD

Obinna Oleribe is affiliated with the Family Services Department, Klamath Tribal Health \& Family Services, Klamath Falls, Oregon. Olatayo Olawepo is affiliated with the Office of the Central Secretariat, Georgetown Global Health, Abuja, Nigeria. Oliver Ezechi is affiliated with the Office of the Central Secretariat, Nigeria Institute for Medical Research (NIMR), Yaba, Lagos, Nigeria. Princess Osita-Oleribe is affiliated with the Child Health Department, Centre for Family Health Initiative (CFHI), Abuja, Nigeria. Michael Fertleman is affiliated with the Cutrale Perioperative \& Ageing Group, Dept of Bioengineering, Imperial College London, London, United Kingdom. Simon D Taylor-Robinson is affiliated with the Department of Surgery and Cancer, Imperial College London, London, United Kingdom. Pease address all correspondence to: Michael Fertleman, Group Leader, Cutrale Perioperative \& Ageing Group, Department of Bioengineering, Imperial College London, White City Campus, 86 Wood Lane, London W12 0BZ, UK. Email: m.fertleman@imperial.ac.uk .

Running Head: COVID-19 in Nigeria 2020-2021

Abbreviations: $\mathrm{CFR}=$ case fatality rate; DR Congo $=$ Democratic Republic of Congo; FCT $=$ Federal Capital Territory; NCDC = Nigerian Center for Disease Control; SARS-CoV-2 = severe acute respiratory syndrome coronavirus 2; WHO = World Health Organization 
Abstract: We report the COVID-19 experience across Nigeria from March 2020 to March 2021. Demographics were obtained from Nigerian Center for Disease Control. By 21 March 2021, 161,737 people were confirmed positive for SARS-COV-2. Overall, testing rates were $0.8 \%$ of the population, with positivity rates of $9.6 \%$, complete recovery rates without long-term sequelae of $91.4 \%$, and case fatality rates of $1.3 \%$. Most Nigerian regions contributed to figures for recent cases and deaths in 2021. The picture may change as testing is scaled-up to include community testing. Given so-called "pandemic fatigue" among the general population, various conspiracy theories being prevalent, and the recent introduction of COVID-19 vaccines in Nigeria, we assume that Nigeria is at a pivotal stage of the outbreak. Effort must be made by government to learn successful strategies in other countries to adapt to prevent a rise in case numbers and deaths.

Key words: COVID-19, Nigeria, epidemiology, pandemic. 
In December 2019, China reported a cluster of pneumonia cases of unknown cause that would later be identified as severe acute respiratory syndrome coronavirus 2 (SARS-CoV-2). ${ }^{1}$ Since then, the infection has spread rapidly across the globe, resulting in the World Health Organization (WHO) declaring a pandemic on 11 March 2020. COVID-19 progressed with unprecedented rapidity around the world. There were $122,524,424$ confirmed documented cases and 2,703,620 documented deaths in 216 nations as of 21 March 2021 with a case fatality rate (CFR) of $2.2 \% .{ }^{2}$ Comparisons have been made between COVID-19 and other pandemics, such as the 1918 flu pandemic (known as "Spanish flu") that infected about onethird of the world's population, killing between 40-50 million people. . $^{3,4}$

COVID-19 has, relatively speaking, spared the African continent in comparison with Europe and the Americas. There were only 2,999,152 cases (which accounted for $2.4 \%$ of global case burden) and 76,113 deaths in Africa over the same period with a CFR of $2.5 \% .{ }^{2,5}$ Theories proposed to explain the unexpectedly low COVID-19 numbers in Africa include the scarcity of large-scale testing and reporting, limited travel connections, effective border screening, and the vulnerability of the virus to Africa's hot climate. ${ }^{4,6}$

Nigeria is of interest epidemiologically speaking as it is Africa's most populous country and has had much experience dealing rapidly and effectively with other viral disease outbreaks, such as the Ebola, Lassa fever, and Marburg viral diseases. Medical services in Nigeria have been accustomed to viral containment with these conditions, so it might be expected that health care services in the country would be prepared for effective action in the COVID-19 pandemic. 
Forthcoming: J. of Health Care for the Poor and Underserved 33.1 (Feb 2022). All rights reserved.

While it may be premature to estimate the final death toll of COVID-19, the global response to the pandemic will determine the final outcome. ${ }^{3}$ As a new disease in Nigeria that is yet to be properly characterized, it is important to determine the epidemiological characteristics of the current COVID-19 outbreak in the country, as it acts as a paradigm for Africa as a whole.

In this study, we document the epidemiological characteristics of the COVID-19 pandemic in Africa's most ethnically diverse country, Nigeria, during the first year of the pandemic.

\section{Methods}

Data acquired for this study were obtained from the Nigeria Centre for Disease Control (NCDC), which is the country's national public health institute, with the mandate to lead the preparedness, detection, and response to infectious disease outbreaks and public health emergencies. ${ }^{7}$ Established in 2001, its founding precepts were signed into law in November 2018 with a mission to "protect the health of Nigerians through evidence-based prevention, integrated disease surveillance and response activities, using a one health approach, guided by research and led by a skilled workforce". ${ }^{7}$ [https://ncdc.gov.ng/ncdc] The core functions of NCDC include (i) to prevent, detect, and control diseases of public health importance; (ii) to coordinate surveillance systems to collect, analyse, and interpret data on diseases of public health importance; (iii) to support constituent Nigerian States in responding to small outbreaks and to lead the response to large disease outbreaks; (iv) to develop and maintain a network of reference and specialized laboratories; (v) to conduct, collate, synthesize, and disseminate public health research to inform policy; and (vi) to lead Nigeria's engagement with the international community on diseases of public health relevance. ${ }^{6}$ 
Forthcoming: J. of Health Care for the Poor and Underserved 33.1 (Feb 2022). All rights reserved.

Since its inception, NCDC has become the core investigation agency for all epidemics in Nigeria including Ebola viral disease, Lassa Fever, cholera, and recently COVID-19. ${ }^{7}$ The NCDC is also the key custodian of epidemiological data in Nigeria and provides information for all epidemiological analysis with free and unlimited access.

Data posted on NCDC website are cleaned and double-checked by Nigerian national epidemiologists and data experts before being uploaded to the NCDC website for public availability and use.

Key demographic data of the Nigerian COVID-19 cases from 27 February 2020 (when the index case was reported) to 21 March 2021 were obtained from the NCDC website. ${ }^{7}$ The COVID-19 dashboard and the NCDC weekly situation report were also reviewed. ${ }^{7}$ The obtained data were entered into a spreadsheet and analysed using Microsoft Excel (Mountain View, CA, USA). Results were mainly descriptive and reported in narratives, tables, figures, and charts from the data obtained from NCDC.

\section{Results}

During the first-year review period, the epidemic increased, with the highest number of cases reported in February 2021 (Figure 1). A total of 1,684,305 people has been screened for COVID-19 in Nigeria with 161,737 confirmed cases arising from the 36 constituent Nigerian States and from the Federal Capital Territory (FCT) (Table 1 and Figure 2), with a positive test rate of $9.6 \%$. This represents $0.8 \%$ of the Nigerian population of $219,463,000 .^{8}$ Of the total number of people diagnosed positive, 147,899 people ( $91.4 \%)$ were discharged from care without long term issues, and 2,030 people died for a case fatality rate of $1.3 \%$. Five Nigerian States accounted for $58.6 \%$ of the total cases: Lagos ( $n=57,273 ; 35.4 \%)$; FCT $(n=19,580$; 
12.1\%); Plateau ( $n=9,006 ; 5.6 \%)$; and Kaduna $(n=8,858 ; 5.5 \%)$. Similarly, six Nigerian States accounted for $54.1 \%$ of all deaths: Lagos $(n=426$, State, $21.0 \%$; CFR=0.7\%); Edo $(n=192$;

9.5\%; case fatality rate $[C F R]=3.9 \%) ; F C T(n=156 ; 7.7 \% ; C F R=0.8 \%)$; Oyo $(n=116 ; 5.7 \%$; CFR $=1.7 \%)$; Kano $(n=110 ; 5.4 \% ; C F R=2.8 \%)$; and River $(n=98 ; 4.8 \% ; C F R=1.4 \%)$. Ten States have had very high CFR above 3\%: Kogi (40.0\%); Cross River (4.8\%); Edo (3.9\%); Sokoto (3.6\%); Kebbi (3.6\%); Zamfara (3.5\%); Adamawa (3.3\%); Jigawa (3.2\%); Bayelsa (3.1\%); and Yobe (3.1\%). Seventy percent of these States are located in the northern part of the country.

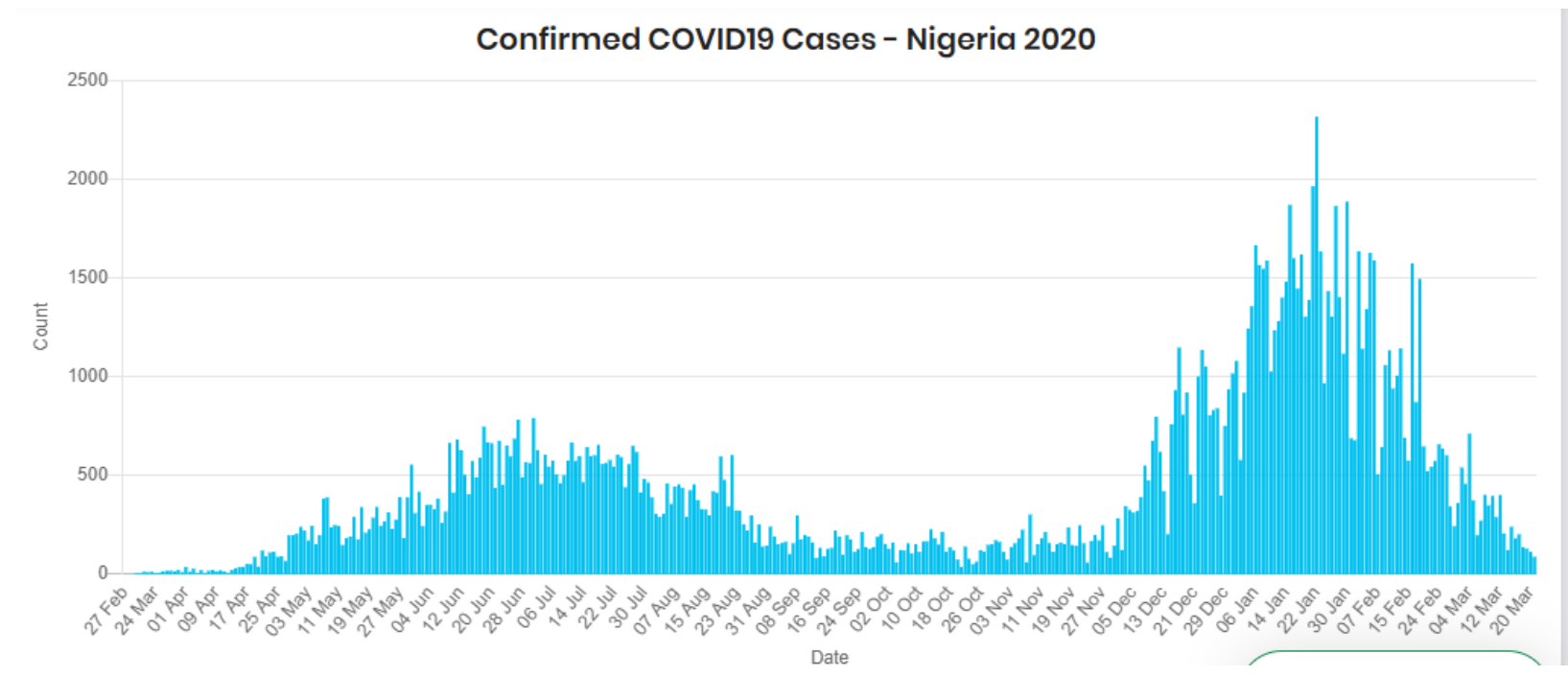

Figure 1. Epidemic curve of COVID-19 in Nigeria (February 27 th - March 21, 2021). Source. Nigeria Center for Disease Control (NCDC), Abuja Nigeria. 


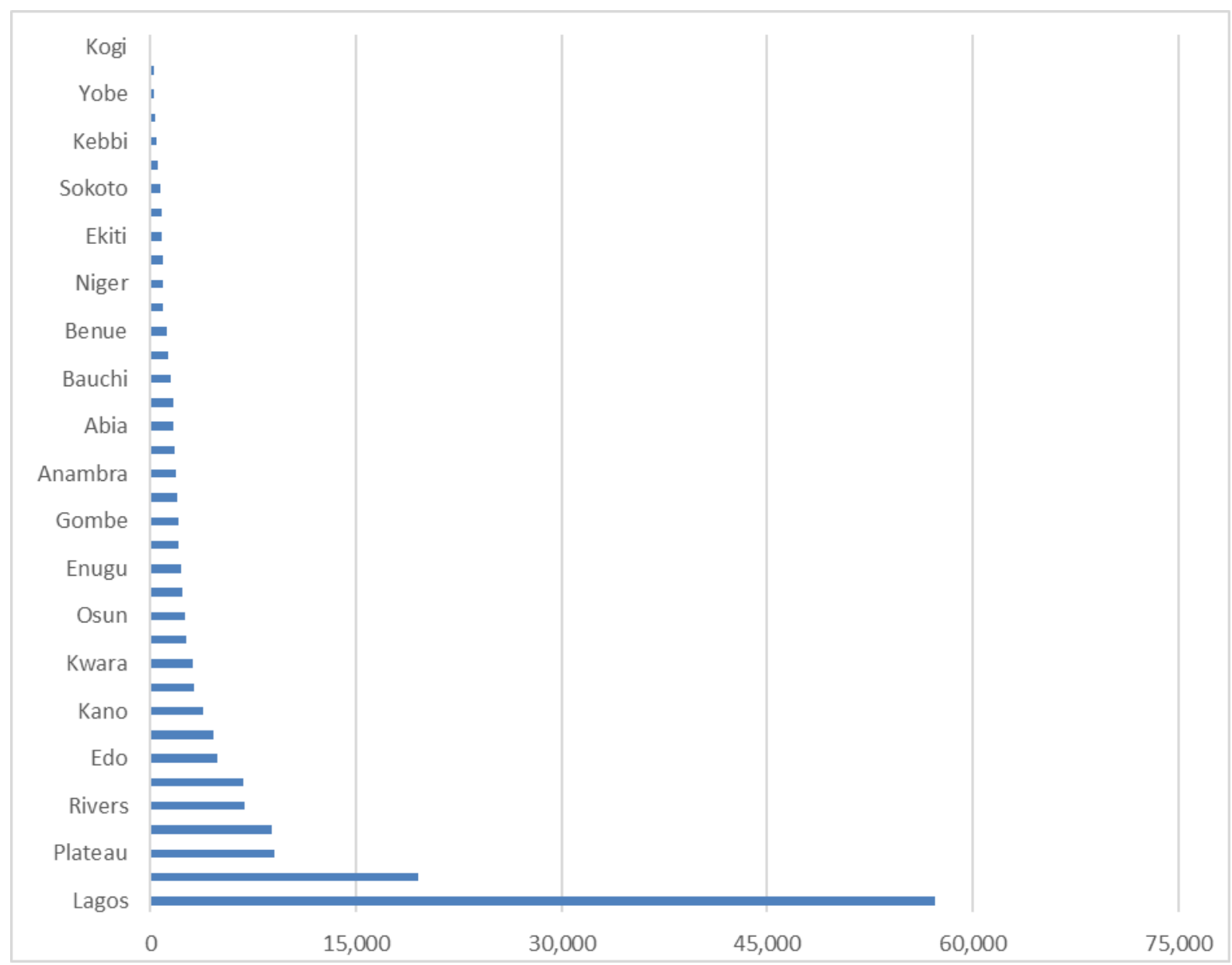

Figure 2. COVID-19 Disease incidence across a representative selection of the 36 Nigerian States, March 21, 2021.

Source: Nigeria Center for Disease Control (NCDC), Abuja Nigeria.

\section{Table 1.}

COVID-19 CUMULATIVE, NEW DISCHARGES AND DEATHS IN EACH NIGERIAN STATE (MARCH 21, 2021)

\begin{tabular}{|c|c|c|c|c|c|c|c|c|}
\hline & States Affected & No. of Cases (Lab Confirmed) & No. of Cases (on admission) & No. Discharged & No. of Deaths & Cum Cases & $\%$ Cum & $\%$ Total Cases \\
\hline 1 & Lagos & 57,273 & 60 & 56,787 & 426 & 57,273 & $35.4 \%$ & $35.4 \%$ \\
\hline 2 & FCT & 19,580 & 3,534 & 15,890 & 156 & 76,853 & $47.5 \%$ & $12.1 \%$ \\
\hline
\end{tabular}




\begin{tabular}{|c|c|c|c|c|c|c|c|c|}
\hline 3 & Plateau & 9,006 & 62 & 8,887 & 57 & 85,859 & $53.1 \%$ & $5.6 \%$ \\
\hline 4 & Kaduna & 8,858 & 84 & 8,709 & 65 & 94,717 & $58.6 \%$ & $5.5 \%$ \\
\hline 5 & Rivers & 6,855 & 113 & 6,644 & 98 & 101,572 & $62.8 \%$ & $4.2 \%$ \\
\hline 6 & Oyo & 6,823 & 503 & 6,204 & 116 & 108,395 & $67.0 \%$ & $4.2 \%$ \\
\hline 7 & Edo & 4,868 & 79 & 4,597 & 192 & 113,263 & $70.0 \%$ & $3.0 \%$ \\
\hline 8 & Ogun & 4,610 & 241 & 4,320 & 49 & 117,873 & $72.9 \%$ & $2.9 \%$ \\
\hline 9 & Kano & 3,889 & 27 & 3,752 & 110 & 121,762 & $75.3 \%$ & $2.4 \%$ \\
\hline 10 & Ondo & 3,157 & 1,002 & 2,094 & 61 & 124,919 & $77.2 \%$ & $2.0 \%$ \\
\hline 11 & Kwara & 3,067 & 204 & 2,808 & 55 & 127,986 & $79.1 \%$ & $1.9 \%$ \\
\hline 12 & Delta & 2,599 & 784 & 1,744 & 71 & 130,585 & $80.7 \%$ & $1.6 \%$ \\
\hline 13 & Osun & 2,508 & 55 & 2,401 & 52 & 133,093 & $82.3 \%$ & $1.6 \%$ \\
\hline 14 & Nasarawa & 2,316 & 1,930 & 373 & 13 & 135,409 & $83.7 \%$ & $1.4 \%$ \\
\hline 15 & Enugu & 2,221 & 327 & 1,865 & 29 & 137,630 & $85.1 \%$ & $1.4 \%$ \\
\hline 16 & Katsina & 2,082 & 18 & 2,030 & 34 & 139,712 & $86.4 \%$ & $1.3 \%$ \\
\hline 17 & Gombe & 2,025 & 3 & 1,978 & 44 & 141,737 & $87.6 \%$ & $1.3 \%$ \\
\hline 18 & Ebonyi & 1,985 & 15 & 1,938 & 32 & 143,722 & $88.9 \%$ & $1.2 \%$ \\
\hline 19 & Anambra & 1,909 & 64 & 1,826 & 19 & 145,631 & $90.0 \%$ & $1.2 \%$ \\
\hline 20 & Akwa lbom & 1,736 & 441 & 1,281 & 14 & 147,367 & $91.1 \%$ & $1.1 \%$ \\
\hline
\end{tabular}




\begin{tabular}{|c|c|c|c|c|c|c|c|c|}
\hline 21 & Abia & 1,649 & 9 & 1,619 & 21 & 149,016 & $92.1 \%$ & $1.0 \%$ \\
\hline 22 & Imo & 1,639 & 68 & 1,535 & 36 & 150,655 & $93.1 \%$ & $1.0 \%$ \\
\hline 23 & Bauchi & 1,488 & 204 & 1,267 & 17 & 152,143 & $94.1 \%$ & $0.9 \%$ \\
\hline 24 & Borno & 1,325 & 87 & 1,200 & 38 & 153,468 & $94.9 \%$ & $0.8 \%$ \\
\hline 25 & Benue & 1,188 & 575 & 591 & 22 & 154,656 & $95.6 \%$ & $0.7 \%$ \\
\hline 26 & Adamawa & 942 & 641 & 270 & 31 & 155,598 & $96.2 \%$ & $0.6 \%$ \\
\hline 27 & Niger & 930 & 496 & 417 & 17 & 156,528 & $96.8 \%$ & $0.6 \%$ \\
\hline 28 & Taraba & 910 & 24 & 864 & 22 & 157,438 & $97.3 \%$ & $0.6 \%$ \\
\hline 29 & Ekiti & 863 & 53 & 799 & 11 & 158,301 & $97.9 \%$ & $0.5 \%$ \\
\hline 30 & Bayelsa & 832 & 27 & 779 & 26 & 159,133 & $98.4 \%$ & $0.5 \%$ \\
\hline 31 & Sokoto & 773 & 4 & 741 & 28 & 159,906 & $98.9 \%$ & $0.5 \%$ \\
\hline 32 & Jigawa & 503 & 7 & 480 & 16 & 160,409 & $99.2 \%$ & $0.3 \%$ \\
\hline 33 & Kebbi & 442 & 34 & 392 & 16 & 160,851 & $99.5 \%$ & $0.3 \%$ \\
\hline 34 & Cross River & 357 & 6 & 334 & 17 & 161,208 & $99.7 \%$ & $0.2 \%$ \\
\hline 35 & Yobe & 293 & 25 & 259 & 9 & 161,501 & $99.9 \%$ & $0.2 \%$ \\
\hline 36 & Zamfara & 231 & 2 & 221 & 8 & 161,732 & $100.0 \%$ & $0.1 \%$ \\
\hline 37 & Kogi & 5 & 0 & 3 & 2 & 161,737 & $100.0 \%$ & $0.0 \%$ \\
\hline
\end{tabular}

\section{Source: Nigeria Center for Disease Control (NCDC), Abuja Nigeria}


By the end of February 2021, out of a total of 134,582 cases, the majority of COVID-19 cases were males $(80,534 ; 59.8 \%)$ (Figure 3, Table 2), while people within the $25-44$ age group accounted for over $50 \%$ of all cases. The highest CFR was seen in those above 70 years of age and below 10 years as follows; 85 years and older (10.2\%); $80-84(9.6 \%) ; 75-79$ (5.7\%); $70-74$ (3.0\%); $0-4(3.4 \%) ;$ and $5-9$ (2.4\%) (Table 2$)$. 
Forthcoming: J. of Health Care for the Poor and Underserved 33.1 (Feb 2022). All rights reserved.

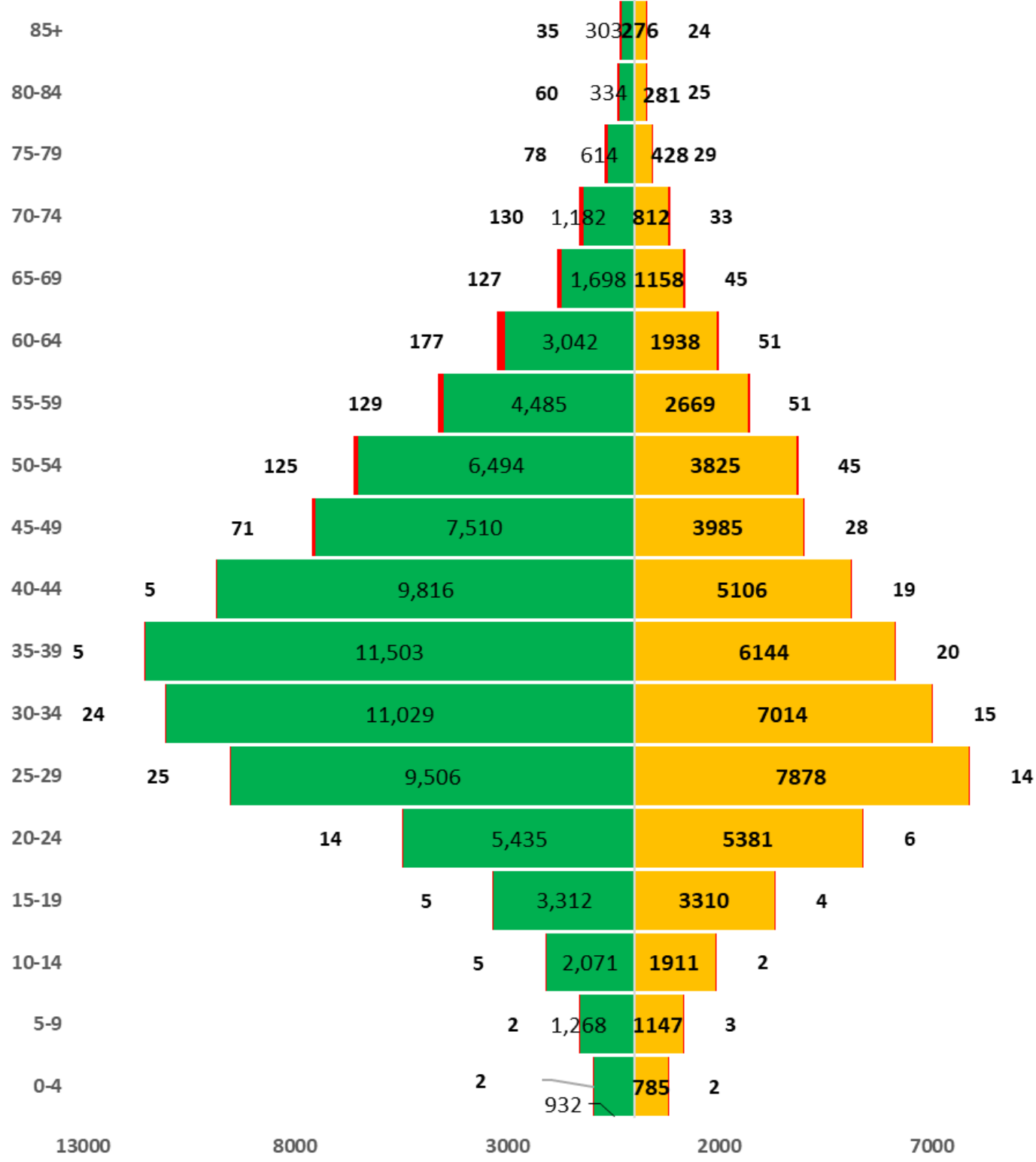

12000

Figure 3a. Age-sex distribution of COVID-19 cases in Nigeria to March 2021.

Source: Nigeria Center for Disease Control (NCDC), Abuja Nigeria 


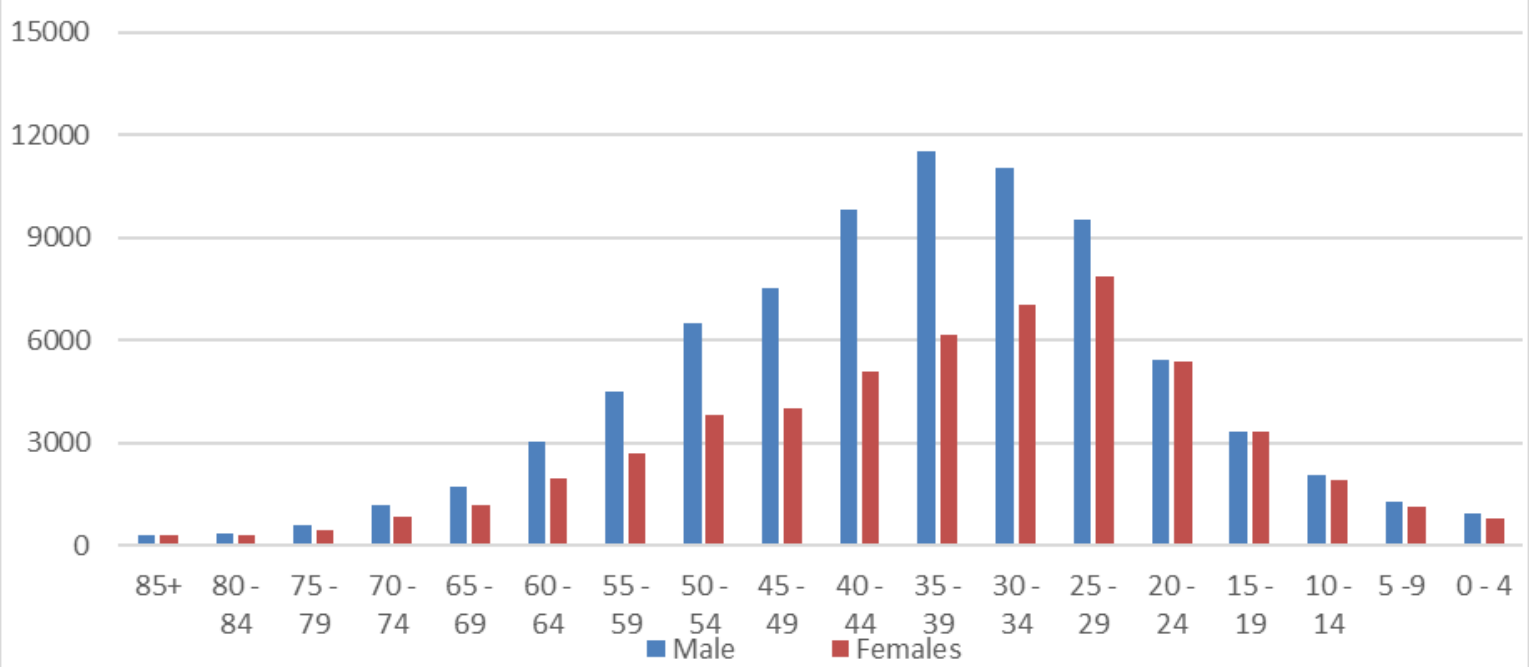

Figure 3b: Age and Sex distribution of COVID-19 cases in Nigeria as at March 21, 2021. Source: Nigeria Center for Disease Control (NCDC), Abuja Nigeria

Table 2.

MALE TO FEMALE CASE INCIDENCE AND DEATH RATES IN ALL AGE GROUPS AS OF FEBRUARY 28, 2021

\begin{tabular}{|c|c|c|c|c|c|c|c|c|c|c|c|c|c|}
\hline & & ses & & & & aths & & & & & & & \\
\hline Age Group & Male & Females & Total & $\%$ Cases & Males & Females & Total & CFR & \% Deaths & $\%$ Male & $\%$ Female & CFR male & CFR Female \\
\hline $85+$ & 303 & 276 & 579 & $0.4 \%$ & 35 & 24 & 59 & $10.2 \%$ & $4.1 \%$ & $52.3 \%$ & $47.7 \%$ & $11.6 \%$ & $8.7 \%$ \\
\hline $80-84$ & 334 & 281 & 615 & $0.5 \%$ & 60 & 25 & 85 & $9.6 \%$ & $5.9 \%$ & $54.3 \%$ & $45.7 \%$ & $18.0 \%$ & $8.9 \%$ \\
\hline $75-79$ & 614 & 428 & 1042 & $0.8 \%$ & 78 & 29 & 107 & $5.7 \%$ & $7.5 \%$ & $58.9 \%$ & $41.1 \%$ & $12.7 \%$ & $6.8 \%$ \\
\hline $70-74$ & 1182 & 812 & 1994 & $1.5 \%$ & 130 & 33 & 163 & $3.0 \%$ & $11.4 \%$ & $59.3 \%$ & $40.7 \%$ & $11.0 \%$ & $4.1 \%$ \\
\hline $65-69$ & 1698 & 1158 & 2856 & $2.1 \%$ & 127 & 45 & 172 & $2.1 \%$ & $12.0 \%$ & $59.5 \%$ & $40.5 \%$ & $7.5 \%$ & $3.9 \%$ \\
\hline $60-64$ & 3042 & 1938 & 4980 & $3.7 \%$ & 177 & 51 & 228 & $1.2 \%$ & $15.9 \%$ & $61.1 \%$ & $38.9 \%$ & $5.8 \%$ & $2.6 \%$ \\
\hline
\end{tabular}




\begin{tabular}{|c|c|c|c|c|c|c|c|c|c|c|c|c|c|}
\hline $55-59$ & 4485 & 2669 & 7154 & $5.3 \%$ & 129 & 51 & 180 & $0.8 \%$ & $12.6 \%$ & $62.7 \%$ & $37.3 \%$ & $2.9 \%$ & $1.9 \%$ \\
\hline $50-54$ & 6494 & 3825 & 10319 & $7.7 \%$ & 125 & 45 & 170 & $0.6 \%$ & $11.9 \%$ & $62.9 \%$ & $37.1 \%$ & $1.9 \%$ & $1.2 \%$ \\
\hline $45-49$ & 7510 & 3985 & 11495 & $8.5 \%$ & 71 & 28 & 99 & $0.5 \%$ & $6.9 \%$ & $65.3 \%$ & $34.7 \%$ & $0.9 \%$ & $0.7 \%$ \\
\hline $40-44$ & 9816 & 5106 & 14922 & $11.1 \%$ & 5 & 19 & 24 & $0.4 \%$ & $1.7 \%$ & $65.8 \%$ & $34.2 \%$ & $0.1 \%$ & $0.4 \%$ \\
\hline $35-39$ & 11503 & 6144 & 17647 & $13.1 \%$ & 5 & 20 & 25 & $0.3 \%$ & $1.7 \%$ & $65.2 \%$ & $34.8 \%$ & $0.0 \%$ & $0.3 \%$ \\
\hline $30-34$ & 11029 & 7014 & 18043 & $13.4 \%$ & 24 & 15 & 39 & $0.3 \%$ & $2.7 \%$ & $61.1 \%$ & $38.9 \%$ & $0.2 \%$ & $0.2 \%$ \\
\hline $25-29$ & 9506 & 7878 & 17384 & $12.9 \%$ & 25 & 14 & 39 & $0.3 \%$ & $2.7 \%$ & $54.7 \%$ & $45.3 \%$ & $0.3 \%$ & $0.2 \%$ \\
\hline $20-24$ & 5435 & 5381 & 10816 & $8.0 \%$ & 14 & 6 & 20 & $0.5 \%$ & $1.4 \%$ & $50.2 \%$ & $49.8 \%$ & $0.3 \%$ & $0.1 \%$ \\
\hline $15-19$ & 3312 & 3310 & 6622 & $4.9 \%$ & 5 & 3 & 8 & $0.9 \%$ & $0.6 \%$ & $50.0 \%$ & $50.0 \%$ & $0.2 \%$ & $0.1 \%$ \\
\hline $10-14$ & 2071 & 1911 & 3982 & $3.0 \%$ & 5 & 2 & 7 & $1.5 \%$ & $0.5 \%$ & $52.0 \%$ & $48.0 \%$ & $0.2 \%$ & $0.1 \%$ \\
\hline $5-9$ & 1268 & 1147 & 2415 & $1.8 \%$ & 2 & 3 & 5 & $2.4 \%$ & $0.3 \%$ & $52.5 \%$ & $47.5 \%$ & $0.2 \%$ & $0.3 \%$ \\
\hline $0-4$ & 932 & 785 & 1717 & $1.3 \%$ & 2 & 2 & 4 & $3.4 \%$ & $0.3 \%$ & $54.3 \%$ & $45.7 \%$ & $0.2 \%$ & $0.3 \%$ \\
\hline Total & 80534 & 54048 & 134582 & $100.0 \%$ & 1019 & 415 & 1434 & $0.0 \%$ & $100.0 \%$ & $59.8 \%$ & $40.2 \%$ & $1.3 \%$ & $0.8 \%$ \\
\hline
\end{tabular}

\section{Source: Nigeria Center for Disease Control (NCDC), Abuja Nigeria}

Of the positive cases in the first six months of the COVID-19 outbreak, $850(1 \%)$ had a travel history, 12.894 (24\%) were contacts of positive cases, 40,999 (75\%) had no known epidemiologic link. 
Forthcoming: J. of Health Care for the Poor and Underserved 33.1 (Feb 2022). All rights reserved.

The cumulative new discharges and deaths by state are presented in Table 1. All 36 states and the FCT recorded COVID-19 case and deaths (Figure 4). Twelve states (Lagos, FCT, Plateau, Kaduna, Rivers, Oyo, Edo, Ogun, Kano, Ondo, Kwara, Delta) contributed over 80\% $(n=130,585 ; 80.7 \%)$, with Lagos (35.4\%), and the Federal Capital Territory $(12.1 \%)$ reporting the highest number of cases. However, Kogi $(n=5)$, Cross River $(n=357)$ and Edo $(n=4868)$ with relatively fewer cases have higher case fatality rates of $40.0 \%(n=2), 4.8 \%(n=17)$, and 3.9\% ( $n=192)$, respectively. Countries with higher COVID-19 testing also have higher COVID-19 burden (Table 3).

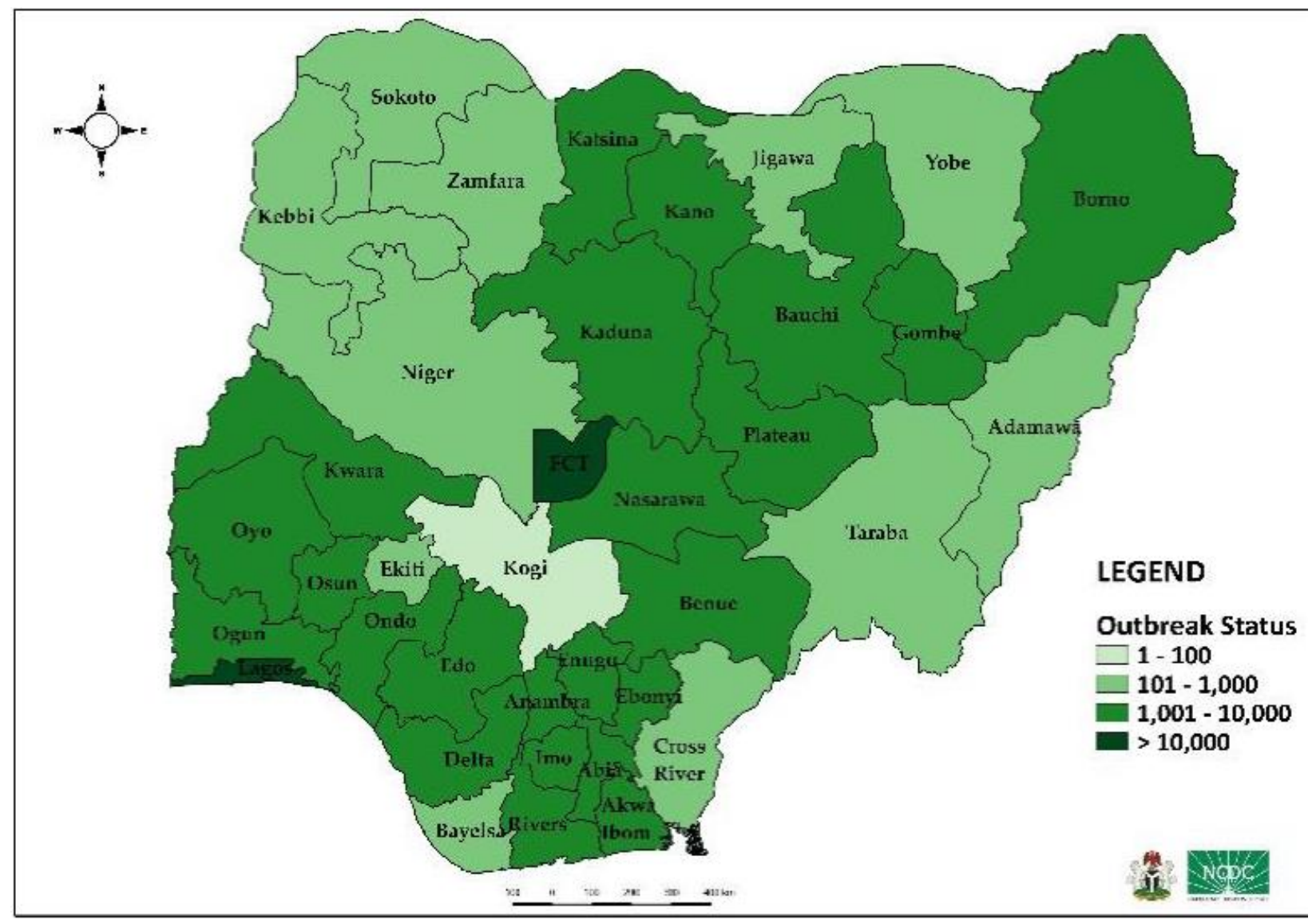

Figure 4. Geographic spread of confirmed cases of COVID-19 in Nigeria, March 21, 2021.

Source: Nigeria Center for Disease Control (NCDC), Abuja Nigeria.

Table 3. 
Forthcoming: J. of Health Care for the Poor and Underserved 33.1 (Feb 2022). All rights reserved.

GLOBAL COVID -19 CUMULATIVE BURDEN BY COUNTRIES (MARCH 21, 2021)

\begin{tabular}{|c|c|c|c|c|c|c|}
\hline & Country & Population & Total Cases & $\%$ & Deaths & CFR \\
\hline 1 & $\underline{\text { USA }}$ & $\underline{332,399,717}$ & $30,521,765$ & $9.2 \%$ & 555,314 & $1.8 \%$ \\
\hline 3 & $\underline{\text { India }}$ & $\underline{1,389,753,146}$ & $11,645,719$ & $0.8 \%$ & 160,003 & $1.4 \%$ \\
\hline 88 & $\underline{\text { China }}$ & $1,439,323,776$ & 90,106 & $0.0 \%$ & 4,636 & $5.1 \%$ \\
\hline 4 & $\underline{\text { Russia }}$ & $\underline{145,979,602}$ & $4,456,869$ & $3.1 \%$ & 95,030 & $2.1 \%$ \\
\hline 5 & $\underline{\text { UK }}$ & $\underline{68,142,752}$ & $4,296,583$ & $6.3 \%$ & 126,155 & $2.9 \%$ \\
\hline 6 & France & $\underline{65,377,629}$ & $4,282,603$ & $6.6 \%$ & 92,305 & $2.2 \%$ \\
\hline 10 & Germany & $\underline{83,976,984}$ & $2,670,000$ & $3.2 \%$ & 75,270 & $2.8 \%$ \\
\hline 7 & $\underline{\text { Italy }}$ & $\underline{60,397,644}$ & $3,376,376$ & $5.6 \%$ & 104,942 & $3.1 \%$ \\
\hline 8 & $\underline{\text { Spain }}$ & $\underline{46,767,842}$ & $3,212,332$ & $6.9 \%$ & 72,910 & $2.3 \%$ \\
\hline 9 & Turkey & $\underline{84,990,883}$ & $3,013,122$ & $3.5 \%$ & 30,061 & $1.0 \%$ \\
\hline 40 & $\underline{\text { UAE }}$ & $\underline{9,976,178}$ & 440,355 & $4.4 \%$ & 1,438 & $0.3 \%$ \\
\hline 2 & Brazil & $\underline{213,646,386}$ & $11,998,233$ & $5.6 \%$ & 294,115 & $2.5 \%$ \\
\hline 22 & Canada & $37,980,039$ & 933,785 & $2.5 \%$ & 22,676 & $2.4 \%$ \\
\hline 59 & Denmark & $\underline{5,806,898}$ & 225,505 & $3.9 \%$ & 2,400 & $1.1 \%$ \\
\hline
\end{tabular}


Forthcoming: J. of Health Care for the Poor and Underserved 33.1 (Feb 2022). All rights reserved.

\begin{tabular}{|c|c|c|c|c|c|c|}
\hline 114 & Australia & $\underline{25,712,304}$ & 29,205 & $0.1 \%$ & 909 & $3.1 \%$ \\
\hline 42 & $\underline{\text { Saudi Arabia }}$ & $\underline{35,202,414}$ & 385,020 & $1.1 \%$ & 6,609 & $1.7 \%$ \\
\hline 26 & Israel & $9,197,590$ & 827,772 & $9.0 \%$ & 6,092 & $0.7 \%$ \\
\hline 11 & Colombia & $\underline{51,272,436}$ & $2,337,150$ & $4.6 \%$ & 62,028 & $2.7 \%$ \\
\hline 15 & Iran & $\underline{84,764,382}$ & $1,801,065$ & $2.1 \%$ & 61,797 & $3.4 \%$ \\
\hline 20 & Indonesia & $\underline{275,601,156}$ & $1,460,184$ & $0.5 \%$ & 39,550 & $2.7 \%$ \\
\hline
\end{tabular}

Source: Worldometers 2021: https://www.worldometers.info

A year after the pandemic was officially registered, of the 86 new cases documented on March 21, 2021, seven states reported cases: FCT (33), Lagos (28), Ondo (11), Kano (7), Akwa Ibom (3), Rivers (3), and Kaduna (1) with just three states (FCT, Lagos, and Ondo) accounting for over $83 \%$ of all new cases. To date, Kogi (5), Zamfara (231), Yobe (293), and Cross River (357) are the states with the lowest documented number of cases. 


\section{Discussion}

In this study, the overall testing rate in the country was $0.8 \%$, with a positivity rate of $2.5 \%$, recovery rate of $91.4 \%$, and case fatality rate of $1.3 \%$. All states including the Federal Capital Territory (FCT) have reported at least five cases, with 12 of the 36 constituent Nigerian States contributing $80.7 \%$ of all cases and close to $50 \%$ of all deaths. The most affected States are geographically equally distributed between the northern and southern parts of the country. Most of the cases were males (59.8\%) and the greatest number of cases were found in the age group $25-44$ years.

Many African countries including Algeria, Sudan, DR Congo, Somalia, Chad, and Eritrea have poor data on numbers tested, and the testing rates per head of population. ${ }^{9}$ Among 222 countries with testing reports, Nigeria with $0.8 \%$ coverage has had better testing coverage per population than 190 countries worldwide, including most African countries, such as Kenya, Senegal, Zimbabwe, Gambia, Uganda, Ethiopia, Ivory Coast, Congo-Brazzaville, Liberia, Mozambique, Sierra Leone, Guinea, Angola, South Sudan, Malawi, and Egypt. ${ }^{9}$ Some African countries, such as Mali, Burundi, Eritrea, Madagascar, and the Republic of Niger, have better testing rates per population that Nigeria. Countries with identified very high case burdens, such as the U.S., Brazil, India, Russia, U.K., France, Italy, Spain, and Turkey within excess of three million cases have high test-coverage rates. ${ }^{9}$ This is a pointer to the fact that the more people are tested, the more cases may be identified. Nigeria must expand testing to have a better picture of the current pandemic.

Testing in Nigeria, one year since the beginning of the epidemic, is still highly restricted to contacts of positive cases, travelers, and individuals with symptoms of COVID-19. This may skew the results, making men seem to be the most affected population, as men tend to have 
better access to prioritized health care services in Nigeria. Since the onset of COVID-19 transmission in the country, most diagnosed cases have had unknown exposure history (74.9\%). This may be a pointer to either community transmission of COVID-19, or poor datagathering and management from COVID-19 incident team. The rest of the cases either had a travel history or contact with positive cases. In Nigeria, men tend to travel more because sociocultural factors restrict women from jobs and activities that require traveling. If the apparent sex difference in COVID-19 incidence is artifactual, this picture is likely to change as community transmission increases and testing is made more readily available to all, irrespective of age, position, and contact or travel history. It may therefore be too early to conclude that the Nigerian epidemic has a male preponderance, as this may be an artifact of who is screened or may in other ways arise from features of the testing program. However, this conjecture requires further observation to see if male gender or social behaviour places men at higher risk of contracting the infection. With a slightly higher female Nigerian population, ${ }^{10}$ the observation that females make up just $32 \%$ of confirmed cases so far, calls for a more detailed analysis to achieve an explanation. Possibilities include genetic, socioeconomic, or cultural factors. It remains possible too that there is a gender issue in willingness to undergo COVID-19 screening.

The majority of all confirmed cases were in the age group $25-44$ years. This is the most economically active group in Nigerian society and is responsible for most dependent members of the population. This has both economic and social implications. It may also be the reason for the lower case fatality in Nigeria, compared with elsewhere, given that fatality rates are higher for those older than 60 years of age. ${ }^{11-13}$ In Nigeria, most fatalities occurred in those 70 years and older, with the highest fatality among those 85 years and older (10.2\%). Case fatality rates also were slightly high among children younger than 10 years, giving the Nigerian pandemic a bimodal appearance. 
However, the findings concerning age may be due to the fact that the current eligibility criteria for testing hinges on a history of traveling into or out of the country, a capacity to pay for COVID-19 testing, and/or a capacity to contact the COVID-19 incident management team via telephone if there are clinical or suspected symptoms. Young adults between ages $25-44$ years are active and involved in economic activities. They have the right connections and the technological capacity to make the calls, book online appointments, afford the fees for the test, and galvanize a health care response. It is possible to link the high eligibility for testing and greater risk of infection to frequent travelling history and the need to go to work despite the various lockdown or restriction policies. This finding is, however, different from reports from China, where all ages appeared susceptible to COVID-19 without significant gender differences. ${ }^{14}$

Although Lagos State has continued to be the epicenter of the COVID-19 pandemic in Nigeria, the Federal Capital Territory, located in the Northern Central region has contributed significantly to all identified cases, new infections, and deaths since the onset of the outbreak in Nigeria. This may be linked to travel history, governmental concern, and the presence of the Federal Ministry of Health and the NCDC in Abuja (the Nigerian capital city), resulting in more testing centers in these two areas of the country than there are in all other States of Nigeria.

The pandemic in Nigeria started in the southern part of the country (Lagos, the largest city), but new cases are now seen in all regions of Nigeria, making this a generalized outbreak, involving the entire country. However, of the 10 states with the worst CFR, $70 \%$ are in the north of the country and include Kogi (40.0\%), Sokoto and Kebbi (3.6\%), and Zamfara (3.5\%). These mortality figures are far higher than the global average of $2.2 \%$, the African average of $2.5 \%$, and the national average of $1.3 \%$ CFR. There is the need to identify the root cause of the differential geographical spread of the COVID-19 outbreak in Nigeria, as well as factors 
facilitating higher death rates in some locations, especially in the States with highest CFR including Kogi, Cross River, Edo, Sokoto, Kebbi, and Zamfara. The question of whether this finding is linked to cultural, religious, or socioeconomic factors or health-seeking behaviours arises. A detailed qualitative study will help to unravel this. ${ }^{15}$

February 2021 saw the highest number of identified cases since the onset of the pandemic. There has been significant reduction in cases in March 2021. It remains to be seen whether Nigeria has passed the peak of the pandemic, as it now appears that the epidemic overall is gradually declining while community spread maybe increasing. There are a few unanswered questions at the time of writing:

1. Does this epidemic curve depict a single source or a propagated pandemic?

2. Will there be an increase in case findings if testing is expanded to more locations and communities around the country?

3. Is the end of the pandemic in sight or are we just seeing an artificial decline in cases, related to a lack of widespread testing?

4. Is the current introduction of COVID-19 vaccine in Nigeria going to change the outbreak dynamics in the country?

These, and many more questions must be answered through more detailed analysis of the current database curated by the Nigerian Center for Disease Control (NCDC), Abuja Office. A large community-based survey will further clarify the nature of the pandemic.

It is impossible to predict the true epidemiology of COVID- 19 when less than $1 \%$ of the population has been tested for coronavirus infection, when quality testing facilities do not exist in all regions/States, and screening and testing is still limited to contacts of positive cases, 
travel history, and symptomatic cases. Scaling-up testing to anyone and everyone who wants to be tested, as seen in some countries of the world, is vital as the communities that are ignorant of this epidemic are at higher risk of infection. Poorly informed, jobless, and hungry people who do not have access to NCDC hotline numbers are more likely to disobey COVID-19 control policies of social distancing, personal hygiene, use of facemasks, stay-at-home policies, and other environmental and infection control strategies enunciated by NCDC. ${ }^{16,17}$ The scarcity of COVID-19 vaccines and the various conspiracy theories prevalent among the general population may limit the uptake of the COVID-19 vaccine in Nigeria. Moreover, people are beginning to have so-called epidemic policy fatigue and may seek group activities such as going to church, cinema, and shopping complexes, rather than remaining indoors with its associated mental health challenges.

Limited testing puts health care workers at risk, as common diseases in Nigeria appear innocuous with fever, cough, and other COVID-19 symptoms which could be incorrectly diagnosed. Moreover, patients are often untruthful concerning their medical history. ${ }^{18}$

COVID-19 diagnosis in Nigeria is still based on polymerase chain reaction (PCR) one year into the epidemic, a technology that is both costly and requires skilled operators. It could be argued that Nigeria should move testing to the community using simple rapid test kits to maximize use of volunteer health care workers and keep the health care facility-based workers focused on managing endemic health challenges and only confirmed cases.

Health care workers involved in COVID-19 care should restrict their movements and remain in one health care facility as those working in multiple centres (private and public) may carry infection from COVID-19 treatment centres to non-COVID-19 treatment centres, increasing the nosocomial infection rates. ${ }^{19}$ 
While waiting for the expansion of COVID-19 vaccination in Nigeria and effective antiviral therapies against COVID-19, efforts should be made to identify all COVID-19 infected cases (or at least most) and place them in isolation while infectious. To curtail the pandemic with present community transmission continuing to rise in some constituent Nigerian States and communities, community screening, swift and targeted contact tracing with physical isolation, community mobilisation and engagement, early identification and confirmation of cases, and health systems assessment are all necessary to avert the harmful consequences of the COVID19 outbreak in Nigeria. 6,17

Conclusion. The testing rate in Nigeria is low at $0.8 \%$ of the total population, one year into the pandemic, with a young male preponderance, a case positivity of $9.6 \%$, and case fatality rate of $1.3 \%$. Although infection started in the southern part of the country, the outbreak has spread to all States of Nigeria. The picture may change as testing is scaled up to include community-based testing. We assume that the country is now at a pivotal stage of the epidemic with the vaccination program about to start in earnest. Efforts must be made by governments at the state and national level to learn from countries that have properly controlled the infection to control the effects of the pandemic in Nigeria. In addition, testing at community levels should be upscaled using rapid test kits with isolation of identified cases. 


\section{Acknowledgments}

We acknowledge the Nigerian National Emergency Outbreak Committee on COVID-19, the Presidential Task Force (PTF), and the Nigerian Center for Disease Control. Data used for this analysis were retrieved from the NCDC website (https://covid19.ncdc.gov.ng/). We acknowledge all the frontline health care workers who put their lives at risk to control and contain this epidemic. $\mathrm{OOO}$ is grateful to the Excellence and Friends Management Care Centre (EFMC) Team in Abuja, Nigeria for their due diligence, epidemiologic and public health work during this period and to the Klamath Tribal Health \& Family Service (KTH\&FS), Oregon, U.S.A. MF and SDTR are grateful to the NIHR Biomedical Facility at Imperial College London for infrastructural support. SDTR was supported by a Wellcome Trust ISSF grant at Imperial College London.

\section{References}

1. Singh L, Bansal S, Bode L, et al. A first look at COVID-19 information and misinformation sharing on Twitter. Ithaca, NY: ArXiv, Cornell University, 2020 Mar 31. Available at: http://arxiv.org/abs/2003.13907.

2. World Health Organization (WHO). WHO Coronavirus (COVID-19) Dashboard. Geneza, Switzerland: WHO, 2020. Available at: https://covid19.who.int/.

3. Spinney L. How pandemics shape social evolution. Nature. 2019;574(7778):324-6. https://doi.org/10.1038/d41586-019-03048-8

4. Otu A, Ebenso B, Labonte R, et al. Tackling COVID-19: can the African continent play the long game? J Glob Health. 2020 Jun;10(1):010339.

https://doi.org/10.7189/jogh.10.010339

PMid:32373319 PMCid:PMC7182683

5. World Health Organization (WHO). COVID-19 in the WHO African Region. Geneza, 
Switzerland: WHO, 2021. Available at:

https://who.maps.arcgis.com/apps/opsdashboard/index.html\#/0c9b3a8b68d0437a8cf28581e9c06 $3 \mathrm{a} 9$.

6. Martinez-Alvarez M, Jarde A, Usuf E, et al. COVID-19 pandemic in west Africa. Lancet Glob Heal. 2020 May;8(5):e631-2. https://doi.org/10.1016/S2214-109X(20)30123-6

7. Nigeria Centre for Disease Control (NCDC). COVID-19 NIGERIA. Abuja, Nigeria: NCDC, 2021. Available at: https://covid19.ncdc.gov.ng/report/.

8. Central Intelligence Agency (CIA). The World Factbook: Africa, Nigeria. Washington, DC: CIA, 2021. Available at: https://www.cia.gov/the-world-factbook/countries/nigeria/.

9. Woldometer. COVID 19: population. Available at:

https://www.worldometers.info/coronavirus/?utm_campaign=homeAdUOA?Si\%23countries.

10. Country Meters. Nigeria Population. Available at: https://countrymeters.info/en/Nigeria.

11. Ruan Q, Yang K, Wang W, et al. Clinical predictors of mortality due to COVID-19 based on an analysis of data of 150 patients from Wuhan, China. Intensive Care Med. 2020

May;46(5):846-8.

https://doi.org/10.1007/s00134-020-05991-x

PMid:32125452 PMCid:PMC7080116

12. Zhou F, Yu T, Du R, et al. Clinical course and risk factors for mortality of adult inpatients with COVID-19 in Wuhan, China: a retrospective cohort study. Lancet. $2020 \mathrm{Mar}$ 28;395(10229):1054-62. https://doi.org/10.1016/S0140-6736(20)30566-3

13. Singh R, Adhikari R. Age-structured impact of social distancing on the COVID-19 epidemic in India. Ithaca, NY: ArXiv, Cornell University, 2020. Available at: http://arxiv.org/abs/2003.12055.

14. Dong Y, Mo X, Hu Y, et al. Epidemiological characteristics of 2143 pediatric patients with 2019 Coronavirus disease in China. Pediatrics. 2020.

15. Lipsitch M, Swerdlow DL, Finelli L. Defining the epidemiology of Covid-19 - studies needed. N Engl J Med. 2020 Mar 26;382(13):1194-6.

https://doi.org/10.1056/NEJMp2002125

PMid:32074416

16. Wang Y, Wang Y, Chen Y, et al. Unique epidemiological and clinical features of the 
emerging 2019 novel coronavirus pneumonia (COVID-19) implicate special control measures. J Med Virol. 2020 Jun;92(6):568-76.

https://doi.org/10.1002/jmv.25748

PMid:32134116 PMCid:PMC7228347

17. Nigeria Centre for Disease Control (NCDC). Guideline. Abuja, Nigeria: NCDC, 2021. Avail-able at: https://covid19.ncdc.gov.ng/guideline/.

18. Castelo-Branco C, Palacios S, Ferrer-Barriendos J, et al. Do patients lie? An open inter-view vs. A blind questionnaire on sexuality. J Sex Med. 2010;7(2 Pt 2):873-80.

https://doi.org/10.1111/j.1743-6109.2009.01575.x

PMid:19912497

19. McMichael TM, Currie DW, Clark S, et al. Epidemiology of Covid-19 in a long-term care facility in King County, Washington. N Engl J Med. 2020 May 21;382(21):2005-2011.

https://doi.org/10.1056/NEJMoa2005412

PMid:32220208 PMCid:PMC7121761 